\title{
Toward a Reconceptualization of Stem Cells from Cellular Plasticity
}

\author{
Tao Liu', Li Chen ${ }^{2}$, Zhongjian Zhao ${ }^{3}$, Shichang Zhang ${ }^{3}$ \\ ${ }^{1}$ Department of Infectious Diseases, Nary No.971 Hospital (formerly known as No.401 Hospital) of Chinese PLA, Qingdao, China, \\ ${ }^{2}$ Department of Obstetrics, the First Affiliated Hospital of Nanjing Medical University, Nanjing, China, ${ }^{3}$ Department of Laboratory \\ Medicine, the First Affiliated Hospital of Nanjing Medical University, Nanjing, China
}

The slow progress in clinical applications of stem cells and the bewildering mechanisms involved have puzzled many researchers. Recently, the increasing evidences have indicated that cells have superior plasticity in vivo or in vitro, spontaneously or under extrinsic specific inducers. The concept of stem cells may be challenged, or even replaced by the concept of cell plasticity when cell reprogramming technology is progressing rapidly. The characteristics of stem cells are manifestations of cellular plasticity. Incorrect understanding of the concept of stem cells hinders the clinical application of so-called stem cells. Understanding cellular plasticity is important for understanding and treating disease. The above issues will be discussed in detail to prove the reconceptualization of stem cells from cellular plasticity.

Keywords: Stem cells, Plasticity, Differentiation, Dedifferentiation, Transdifferentiation

\section{Introduction}

Stem cells are defined as undifferentiated biological cells that can differentiate into specialized cells and can divide through mitosis to produce more stem cells. We often identify stem cells by detection of cell proliferation ability, directional differentiation ability and specific gene expression (1). However, the concept of stem cells may be challenged, or even replaced by the concept of cell plasticity when cell reprogramming technology is progressing

Received: October 19, 2018, Revised: January 21, 2019, Accepted: January 21, 2019, Published online: February 28, 2019 Correspondence to Shichang Zhang

Department of Laboratory Medicine, the First Affiliated Hospital of Nanjing Medical University, Nanjing 210029, China

Tel: +86-25-6830-3773, Fax: +86-25-6830-3773

E-mail: zsc78@yeah.net

(c) This is an open-access article distributed under the terms of the Creative Commons Attribution Non-Commercial License (http://creativecommons.org/ licenses/by-nc/4.0/), which permits unrestricted non-commercial use, distribution, and reproduction in any medium, provided the original work is properly cited.

Copyright (c) 2019 by the Korean Society for Stem Cell Research rapidly.

Since Shinya Yamanaka (2) created the technology of induced pluripotent stem cells, the study about cell differentiation, dedifferentiation and transdifferentiation progress quickly (3). These progressions suggest that any cells with various differentiation grades may change in variety of forms under certain induction such as transcription factors (4) or small molecules (5). Moreover, this change is not only confirmed by experiments in vitro, but also in vivo (3). The increasing evidences $(6,7)$ show that in vivo, cells can change spontaneously in some specific pathophysiological environment. The cellular super plasticity makes cells distinction and stem cells concept indistinct. Based on above theory, in principle, any types of cell may change or proliferate and contribute to tissue repair and regeneration in some specific environment. These surprising findings may also suggest a hypothesis that concept of stem cells is being redefined. Here, we will discuss the problem from the following aspects. 


\section{The Concept of Stem Cells Is Becoming Increasingly Blurred}

According to the grade and level of differentiation, cells can be divided into embryonic stem cells, adult stem cells and adult cells that seems like tree roots, trunks and leaves, respectively. The previous viewpoint is that this distinction is obvious and the seniority ranking can't be changed. But, rapid progress of cells reprogramming technology in the last ten years has changed the rules of the game. Induced pluripotent stem cells, which may represent embryonic stem cells, adult stem cells and adult cells can be converted mutually through differentiation, dedifferentiation or transdifferentiation. These interesting findings also confuse us just like the logic of chicken and egg. Moreover, certain cells can obtain proliferation ability, directional differentiation ability and specific gene expression under a series of induction. These new understanding actually make the concept of stem cells fuzzy.

In fact, the concept of specific stem cells is often in dispute. A typical example is liver stem cell or progenitor cell, previously known hepatic oval cell $(6,8-18)$. Its existence has been questioned and the exact definition is also still in debate. And its contribution to liver regeneration after liver injury is also a controversial issue $(13,19)$. And the latest cell tracing technique showed that in addition to the so-called liver stem cells, different subsets of the liver cells were also shown to play a role in the regeneration of the liver under different conditions $(13-15,19)$. Some researchers even proposed that all hepatocytes are stem cells (16). These arguments are essentially due to the fuzzy concept of stem cells. When we are trying to find and study liver stem cells, we may have to make our thinking imprisoned. First, we subjectively predetermine some stationary phenotypes and characters for the liver stem cells. Secondly, we are not aware of the fact that liver stem cells may be a virtual concept that does not exist. This erroneous knowledge may also lead us into an endless debate about liver stem cells and liver regeneration.

From the developmental point of view, cell changes are continuous from embryonic stem cells to mature cells. During cellular development, chromatin status will continuously undergo changes and post-transcriptional modifications, causing phenotypic and functional changes on the basis of the same set of genetic material (20). During the process of cell development and differentiation, any cells theoretically can be called stem cells or changed to stem cells so that the concept of stem cells does not exist indeed.

\section{The Characteristics of Stem Cells Are Manifestations of Cellular Plasticity}

Recently, a series of reviews (21-24) together with the editors' comments (17) has been published in HEPATOLOGY to discuss stem cells or reprogramming (plasticity) mechanisms in liver, biliary tree, and pancreas. Scholars try to explore the issue of liver regeneration and repair from the perspective of stem cells or reprogramming mechanisms that reflect the division of opinions. Lots of researchers try to identify, isolate and discover liver stem cells and their contribution to liver regeneration (25). The new technique reveals the cellular plasticity, and finds its important role in the process of tissue regeneration including liver (26). However, it also may induce a new problem or dispute that among stem cells or cellular plasticity, which play the key role during liver regeneration $(10,17,27)$. Indeed, the characteristics of stem cells are just manifestations of cellular plasticity. In other words, the concept of stem cells needs to be redefined and stem cells are only one form of cell plasticity. Recognizing this opinion may let us better understand current controversy on stem cells and tissue regeneration.

As Meritxell Huch's concise review (24) shows, stemness seems not to be limited to a particular cell type but rather to a cellular state in which cells exhibit a high degree of plasticity and can move back and forth in different phenotypic states. They think that stem cell fate and stem cell potential are two different sides of cellular plasticity (24). However, stem cell fate and stem cell potential seem to be a pair of contradictory concepts that are confusing because stem cell is not standard ruler and is just a generalized cellular state. In fact, all about stem cell problems may be explained by cellular plasticity. In evidence-based medicine, clinicians often use a variety of scoring systems to rating the patient's condition. Similarly, we may also evaluate cellular plasticity by a certain score system in the future.

\section{Incorrect Understanding Hinders the Clinical Application of So-called Stem Cells}

Since its first definition, stem cells have been held in high hopes in the field of tissue regeneration and repair, especially in various neurological disorders, such as spinal cord injury, and organ failure, such as liver failure and heart failure. But so far, stem cell therapies have not been able to provide definitive and effective treatment in clinical trials (28). And safety is also a major obstacle to the clinical use of stem cells. Due to the above reasons, so far 
Food and Drug Administration has approved only one stem cell product, Hemacord, a cord blood-derived product that is mainly composed of hematopoietic progenitor cells and used for specified indications in patients with disorders affecting the body's blood-forming system (29). However, hematopoietic progenitor cell transplantation is indeed a kind of blood organ transplantation rather than classical stem cells therapy. The difficulties encountered in the clinical application of stem cells may be due to the incorrect understanding of stem cells. Although there are some successful reports in clinical trials and cases of stem cell clinical treatment (30-32), the exact efficacy, security and the underlying mechanism are still in dispute $(28,33$, 34). Early research hopes to use stem cell proliferation and differentiation to repair the damaged tissue. But recent studies speculate that paracrine or immunomodulatory effects of stem cells may be the basis for stem cell therapy (35-37). These new mechanisms may also bring new doubts: since proliferation and differentiation, which are the two major features of stem cells, contribute little to stem cell therapies, what are the therapeutic implications of stem cells themselves.

Paracrine or immunomodulatory effects of stem cells actually work by changing the plasticity of target cells (36). Therefore, it may lead to a new vision that treating disease by understanding, changing, and using cellular plasticity, rather than relying on the stem cell itself. Many optimistic researchers and related companies in the field of stem cells explain that any great discovery in the scientific field will have to wait for decades and even longer for clinical applications. However, we may overlook a critical issue that the erroneous understanding of the concept of stem cells may be the biggest barrier to its clinical use. Stem cells are only a state and characteristic of cells, and stem cells with different potentials or proliferating abilities are only a manifestation of cells with different levels of plasticity. A correct understanding of cellular plasticity may be the key to understanding the current dilemma of stem cell clinical applications. First of all, cellular plasticity is directly influenced by the internal and external environment of cells. When we transplant stem cell into the body, the environment around the stem cells changes dramatically, and its plasticity changes, and its proliferation and differentiation potential will be greatly reduced. Second, cellular plasticity is interactive. The process of cell development and differentiation is always accompanied by different companion cells that provide a special environment for cells interaction directly or indirectly. Many successful constructions of micro organs may due to the use of cell mixing cultures in three-dimensional en- vironment $(38,39)$. When we artificially isolated stem cells from the body, stem cells themselves lose these interaction and current stem cells may not original stem cells. Cells may show varied degrees of cellular plasticity in different cell populations and environments (40).

\section{Cellular Plasticity Is Totipotent}

Totipotency is the ability of a cell to differentiate into all cell types of an entire organism including the trophoblast lineage in a coordinated and highly complex manner (41). The conventional knowledge is that the only totipotent cells are the zygotes and blastomeres (42). In recent years, progress has proved that, in theory, any type of cell can switch to any other type of cell after proper induction (43). The route of change is diverse, mainly in the following aspects. First, adult stem cells with middle differentiation grade may differentiate to specific somatic cells after certain induction processing. Secondly, mature somatic cells with high differentiation grade may be induced transdifferentiation into specific types of other somatic cells by transcription factors or specific small molecules. In recent years, this strategy has been successfully applied in the transformation of fibroblasts into hepatocytes, nerve cells and cardiomyocytes. Third, somatic cells can also dedifferentiate into induced pluripotent stem cells that can further differentiate into any target cells even including trophoblast lineage cells (44-46).

Moreover, the somatic cells also undergo dedifferentiation into specific adult stem cells, such like that hepatocytes or fibroblasts can be induced into so-called liver stem cells through certain induction. Adult cells can change into specific cells through dedifferentiation, differentiation, transdifferentiation, and other forms. These advances suggest that cells of any differentiation grade can change into a variety of cell types in a variety of ways. The update on the concept or understanding of cell fate changes suggests the blurring of stem cell concepts and the boundaries of cell types.

The cells in vivo also have a high degree of plasticity. The aforementioned cell differentiation, transdifferentiation, dedifferentiation and reprogramming are not only confirmed by in vitro experiments, but also have been effectively demonstrated in vivo by local specific induction agents (Fig. 1). These cell transitions are passively given in vitro or in vivo in the presence of extrinsic inducer, but do cell transitions happen spontaneously in pathological or physiological conditions? It is common that tissue stem cells differentiate into daughter cells, but recent studies have shown that cells can also undergo sponta- 


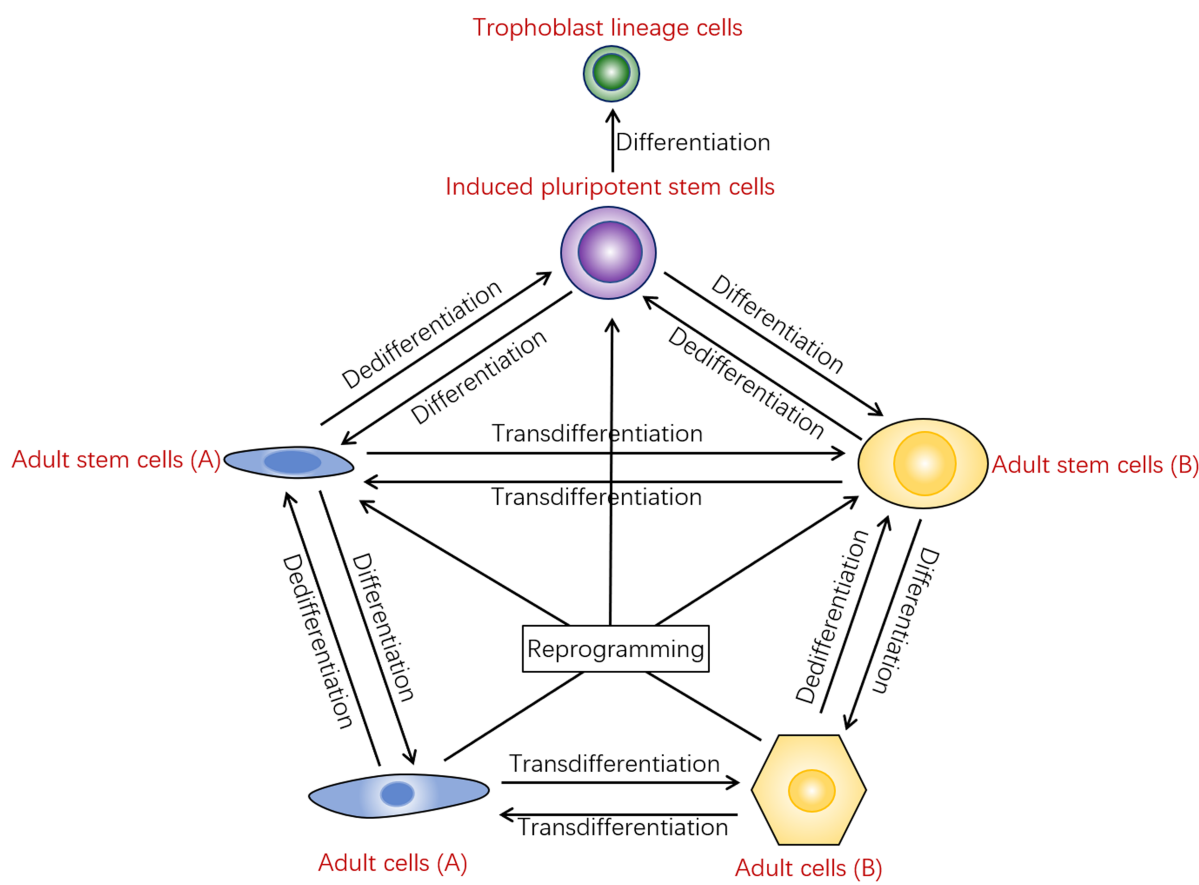

Fig. 1. A schematic diagram of the extensiveness of cellular plasticity. In theory, cells can transform directly or indirectly to any type of cells through differentiation, dedifferentiation, transdifferentiation or reprogramming. neous transdifferentiation and dedifferentiation in vivo $(47,48)$. Cells with short cell renewal cycle such as bone marrow hematopoietic stem cells and intestinal epithelial stem cells constantly differentiate into daughter cells, thus maintaining the balance of tissue regeneration. Recent studies have shown that hepatocytes can also dedifferentiate into hepatic stem cells in the event of injury and promote the repair of injured liver (12). In the course of many tissue damage repair, specific cell populations can spontaneously dedifferentiate into or transdifferentiate into adult cells or adult stem cells (49). Compared with in vitro rapid induction, this transformation is slower and closely related to changes of microenvironment in vivo. These novel findings also demonstrate the universality of cellular plasticity. It also suggests that any type of cell in the body is constantly changing. These changes may be cellular phenotypes, cell morphology or even cell types to meet the needs of the organism. In a particular environment, specific cell populations can change from quantitative change to qualitative change, and undergo spontaneous cell turnover in vivo.

\section{Understanding Cellular Plasticity Is Important for Understanding and Treating Disease}

Understanding cell plasticity can better understand the disease. As the smallest unit of an organism, the proliferation, differentiation and transformation of cells constitute the development, physiological and pathological process of the organism. Cell plasticity not only ensures the process of cell differentiation and development, but also is important for understanding the significance of disease. First of all, in the process of tissue repair, adult cells not only can proliferate under the external stimulation but also can dedifferentiation into stem cells that further proliferate and differentiate to complete the repair of tissue damage process. As tissues are mostly a mixture of many types of cells, in theory, each cell may have a corresponding contribution in the process of tissue injury. Adult stem cells may proliferate and differentiate, and adult cells may dedifferentiate or transdifferentiate to repair damaged tissues. Under different injury conditions, a specific tissue repair procedure may be adopted to improve the tissue repair process. This theory may well explain the current debate about the theory of hepatocyte proliferation in the course of liver tissue repair. Some hepatocytes can self-proliferate, while some hepatocytes can spontaneously reverse into hepatic stem cells, then proliferate, differentiate into hepatocytes, and repair damaged livers. The oval cells, which have the characteristics of liver stem cells, can proliferate or differentiate. And other cellular components in the liver may even be involved in the repair process. Recent studies, for example, suggest that hepatic stellate cells can act as liver stem cells in the repair of liver tissue damage (11).

The application of cellular plasticity may provide new options for the treatment of diseases (50). Understanding the plasticity of cells is important not only for under- 
standing the processes of cell development, differentiation and tissue repair, but also for altering the fate of cells in vivo and in vitro to achieve the purpose of treating diseases. The autologous or allogeneic cells can be transformed into specific target cells by directional differentiation, dedifferentiation, transdifferentiation and gene modification in vitro, and then input into the receptor so as to achieve the purpose of treatment. This model of in vitro manipulation of cells has been largely confirmed by basic studies, and a small number have entered clinical trials. With the further understanding of the cellular plasticity, some studies have suggested that the lesion tissue will be given local stimulation, which can accomplish the passive fate change of target cells in vivo, so as to achieve the purpose of treatment (51). A case in point is the fact that the overexpression of transcription factor hepatocyte nuclear factor 4-alpha in vivo, which plays a key role in hepatocyte differentiation and the maintenance of hepatic function, can alter the performance of hepatocellular carcinoma cells and thereby inhibit the growth of hepatocellular carcinoma cells (52). Although the study mainly is to reveal the pathogenesis of hepatocellular carcinoma, but it presents a new approach for cancer treatment, namely the change of tumor cells, rather than destroy it. Future therapies can also promote tumor control and treatment by giving tumor cells an adequate induction of stimulation or by changing their immune and humoral environment. In vivo, the direct induction of specific cells into neurons (53), cardiomyocytes (54), and hepatocytes (55) has been demonstrated in animal experiments. These findings will shed light on diseases such as diabetes, cardiomyopathy, and nerve injury that related cells previously are considered difficult to regenerate themselves. These findings also bring new hope for fibrotic diseases such as cirrhosis which is difficult to effectively remove fibrous scar tissue by conventional treatment. The increasing evidences indicate that cellular plasticity is ubiquitous in many organs $(50,51,56)$. The cellular plasticity to maintain and repair organs diminishes with age (50). Therefore, new therapeutic approaches to harness cell plasticity will be developed for tissue repair, regeneration and cancer (51).

\section{Acknowledgments}

Supported by the National Natural Science Foundation of China (81671836, 81300507 and 81501817) and the Key Laboratory for Laboratory Medicine of Jiangsu Province of China (ZDXKB2016005).

\section{Potential Conflict of Interest}

The authors have no conflicting financial interest.

\section{References}

1. Potten CS, Loeffler M. Stem cells: attributes, cycles, spirals, pitfalls and uncertainties. Lessons for and from the crypt. Development 1990;110:1001-1020

2. Takahashi K, Yamanaka S. Induction of pluripotent stem cells from mouse embryonic and adult fibroblast cultures by defined factors. Cell 2006;126:663-676

3. Srivastava D, DeWitt N. In vivo cellular reprogramming: the next generation. Cell 2016;166:1386-1396

4. Iwafuchi-Doi M, Zaret KS. Cell fate control by pioneer transcription factors. Development 2016;143:1833-1837

5. Baranek M, Belter A, Naskręt-Barciszewska MZ, Stobiecki M, Markiewicz WT, Barciszewski J. Effect of small molecules on cell reprogramming. Mol Biosyst 2017;13:277-313

6. Yanger K, Zong Y, Maggs LR, Shapira SN, Maddipati R, Aiello NM, Thung SN, Wells RG, Greenbaum LE, Stanger BZ. Robust cellular reprogramming occurs spontaneously during liver regeneration. Genes Dev 2013;27:719-724

7. Cheng CW, Villani V, Buono R, Wei M, Kumar S, Yilmaz $\mathrm{OH}$, Cohen P, Sneddon JB, Perin L, Longo VD. Fastingmimicking diet promotes Ngn3-driven $\beta$-cell regeneration to reverse diabetes. Cell 2017;168:775-788.e12

8. Chen Y, Wong PP, Sjeklocha L, Steer CJ, Sahin MB. Mature hepatocytes exhibit unexpected plasticity by direct dedifferentiation into liver progenitor cells in culture. Hepatology 2012;55:563-574

9. He J, Lu H, Zou Q, Luo L. Regeneration of liver after extreme hepatocyte loss occurs mainly via biliary transdifferentiation in zebrafish. Gastroenterology 2014;146:789-800.e8

10. Hindley CJ, Mastrogiovanni G, Huch M. The plastic liver: differentiated cells, stem cells, every cell? J Clin Invest 2014; 124:5099-5102

11. Kordes C, Sawitza I, Götze S, Herebian D, Häussinger D. Hepatic stellate cells contribute to progenitor cells and liver regeneration. J Clin Invest 2014;124:5503-5515

12. Tarlow BD, Pelz C, Naugler WE, Wakefield L, Wilson EM, Finegold MJ, Grompe M. Bipotential adult liver progenitors are derived from chronically injured mature hepatocytes. Cell Stem Cell 2014;15:605-618

13. Yanger K, Knigin D, Zong Y, Maggs L, Gu G, Akiyama H, Pikarsky E, Stanger BZ. Adult hepatocytes are generated by self-duplication rather than stem cell differentiation. Cell Stem Cell 2014;15:340-349

14. Font-Burgada J, Shalapour S, Ramaswamy S, Hsueh B, Rossell D, Umemura A, Taniguchi K, Nakagawa H, Valasek MA, Ye L, Kopp JL, Sander M, Carter H, Deisseroth K, Verma IM, Karin M. Hybrid periportal hepatocytes regenerate the injured liver without giving rise to cancer. Cell 2015;162:766-779

15. Wang B, Zhao L, Fish M, Logan CY, Nusse R. Self-renewing diploid Axin2(+) cells fuel homeostatic renewal of the liver. Nature 2015;524:180-185 
16. Alison MR, Lin WR. Regenerating the liver: not so simple after all? F1000Res 2016;5:F1000 Faculty Rev-1818.

17. Reid LM. Stem/progenitor cells and reprogramming (plasticity) mechanisms in liver, biliary tree, and pancreas. Hepatology 2016;64:4-7

18. Chen J, Chen L, Zern MA, Theise ND, Diehl AM, Liu P, Duan Y. The diversity and plasticity of adult hepatic progenitor cells and their niche. Liver Int 2017;37:1260-1271

19. Raven A, Lu WY, Man TY, Ferreira-Gonzalez S, O'Duibhir E, Dwyer BJ, Thomson JP, Meehan RR, Bogorad R, Koteliansky V, Kotelevtsev Y, Ffrench-Constant C, Boulter L, Forbes SJ. Cholangiocytes act as facultative liver stem cells during impaired hepatocyte regeneration. Nature 2017;547:350-354

20. Bonifer C, Cockerill PN. Chromatin priming of genes in development: concepts, mechanisms and consequences. Exp Hematol 2017;49:1-8

21. Lanzoni G, Cardinale V, Carpino G. The hepatic, biliary, and pancreatic network of stem/progenitor cell niches in humans: a new reference frame for disease and regeneration. Hepatology 2016;64:277-286

22. Oikawa T. Cancer stem cells and their cellular origins in primary liver and biliary tract cancers. Hepatology 2016;64: 645-651

23. Itoh T. Stem/progenitor cells in liver regeneration. Hepatology 2016;64:663-668

24. Huch M, Dollé L. The plastic cellular states of liver cells: are EpCAM and Lgr5 fit for purpose? Hepatology 2016;64: 652-662

25. Michalopoulos GK, Khan Z. Liver stem cells: experimental findings and implications for human liver disease. Gastroenterology 2015;149:876-882

26. Sen CK. Expanding horizons of cellular plasticity in regenerative medicine. Am J Pathol 2015;185:2592-2595

27. Aloia L, McKie MA, Huch M. Cellular plasticity in the adult liver and stomach. J Physiol 2016;594:4815-4825

28. Marks PW, Witten CM, Califf RM. Clarifying stem-cell therapy's benefits and risks. N Engl J Med 2017;376:10071009

29. Traynor K. FDA approves first stem-cell therapy. Am J Health Syst Pharm 2011;68:2316

30. Kalladka D, Sinden J, Pollock K, Haig C, McLean J, Smith W, McConnachie A, Santosh C, Bath PM, Dunn L, Muir $\mathrm{KW}$. Human neural stem cells in patients with chronic ischaemic stroke (PISCES): a phase 1, first-in-man study. Lancet 2016;388:787-796

31. Ciccocioppo R, Gallia A, Avanzini MA, Betti E, Picone C, Vanoli A, Paganini C, Biagi F, Maccario R, Corazza GR. A refractory celiac patient successfully treated with mesenchymal stem cell infusions. Mayo Clin Proc 2016;91:812-819

32. Mandai $M$, Watanabe A, Kurimoto Y, Hirami Y, Morinaga C, Daimon T, Fujihara M, Akimaru H, Sakai N, Shibata Y, Terada M, Nomiya Y, Tanishima S, Nakamura M, Kamao H, Sugita S, Onishi A, Ito T, Fujita K, Kawamata S, Go MJ, Shinohara C, Hata KI, Sawada M, Yamamoto
M, Ohta S, Ohara Y, Yoshida K, Kuwahara J, Kitano Y, Amano N, Umekage M, Kitaoka F, Tanaka A, Okada C, Takasu N, Ogawa S, Yamanaka S, Takahashi M. Autologous induced stem-cell-derived retinal cells for macular degeneration. N Engl J Med 2017;376:1038-1046

33. Jin J. Stem cell treatments. JAMA 2017;317:330

34. Traverse JH, Henry TD, Pepine CJ, Willerson JT, Ellis SG. One-year follow-up of intracoronary stem cell delivery on left ventricular function following ST-elevation myocardial infarction. JAMA 2014;311:301-302

35. Zhang S, Chen L, Liu T, Zhang B, Xiang D, Wang Z, Wang Y. Human umbilical cord matrix stem cells efficiently rescue acute liver failure through paracrine effects rather than hepatic differentiation. Tissue Eng Part A 2012;18:1352-1364

36. Glembotski CC. Expanding the paracrine hypothesis of stem cell-mediated repair in the heart: when the unconventional becomes conventional. Circ Res 2017;120:772-774

37. Chen L, Zhang J, Yang L, Zhang G, Wang Y, Zhang S. The effects of conditioned medium derived from mesenchymal stem cells cocultured with hepatocytes on damaged hepatocytes and acute liver failure in rats. Stem Cells Int 2018;2018:9156560

38. Takebe T, Sekine K, Enomura M, Koike H, Kimura $M$, Ogaeri T, Zhang RR, Ueno Y, Zheng YW, Koike N, Aoyama S, Adachi Y, Taniguchi H. Vascularized and functional human liver from an iPSC-derived organ bud transplant. Nature 2013;499:481-484

39. Drost J, Clevers H. Translational applications of adult stem cell-derived organoids. Development 2017;144:968-975

40. Zhang S, Liu P, Chen L, Wang Y, Wang Z, Zhang B. The effects of spheroid formation of adipose-derived stem cells in a microgravity bioreactor on stemness properties and therapeutic potential. Biomaterials 2015;41:15-25

41. Do JT, Schöler HR. Regulatory circuits underlying pluripotency and reprogramming. Trends Pharmacol Sci 2009;30:296-302

42. Condic ML. Totipotency: what it is and what it is not. Stem Cells Dev 2014;23:796-812

43. Liu T, Zhang S, Xiang D, Wang Y. Induction of hepatocyte-like cells from mouse embryonic stem cells by lentivirus-mediated constitutive expression of Foxa2/Hnf4a. J Cell Biochem 2013;114:2531-2541

44. Kojima J, Fukuda A, Taira H, Kawasaki T, Ito H, Kuji N, Isaka $\mathrm{K}$, Umezawa A, Akutsu $\mathrm{H}$. Efficient production of trophoblast lineage cells from human induced pluripotent stem cells. Lab Invest 2017;97:1188-1200

45. Yang J, Ryan DJ, Wang W, Tsang JC, Lan G, Masaki H, Gao X, Antunes L, Yu Y, Zhu Z, Wang J, Kolodziejczyk AA, Campos LS, Wang C, Yang F, Zhong Z, Fu B, Eckersley-Maslin MA, Woods M, Tanaka Y, Chen X, Wilkinson AC, Bussell J, White J, Ramirez-Solis R, Reik W, Göttgens B, Teichmann SA, Tam PPL, Nakauchi H, Zou X, Lu L, Liu P. Establishment of mouse expanded potential stem cells. Nature 2017;550:393-397

46. Benchetrit H, Herman S, van Wietmarschen N, Wu T, 
Makedonski K, Maoz N, Yom Tov N, Stave D, Lasry R, Zayat V, Xiao A, Lansdorp PM, Sebban S, Buganim Y. Extensive nuclear reprogramming underlies lineage conversion into functional trophoblast stem-like cells. Cell Stem Cell 2015;17:543-556

47. Merrell AJ, Stanger BZ. Adult cell plasticity in vivo: de-differentiation and transdifferentiation are back in style. Nat Rev Mol Cell Biol 2016;17:413-425

48. Tata PR, Rajagopal J. Cellular plasticity: 1712 to the present day. Curr Opin Cell Biol 2016;43:46-54

49. Deng X, Zhang X, Li W, Feng RX, Li L, Yi GR, Zhang $\mathrm{XN}$, Yin C, Yu HY, Zhang JP, Lu B, Hui L, Xie WF. Chronic liver injury induces conversion of biliary epithelial cells into hepatocytes. Cell Stem Cell 2018;23:114-122.e3

50. Wells JM, Watt FM. Diverse mechanisms for endogenous regeneration and repair in mammalian organs. Nature 2018;557:322-328

51. Lin B, Srikanth P, Castle AC, Nigwekar S, Malhotra R, Galloway JL, Sykes DB, Rajagopal J. Modulating cell fate as a therapeutic strategy. Cell Stem Cell 2018;23:329-341

52. Ning BF, Ding J, Yin C, Zhong W, Wu K, Zeng X, Yang W, Chen YX, Zhang JP, Zhang X, Wang HY, Xie WF.
Hepatocyte nuclear factor 4 alpha suppresses the development of hepatocellular carcinoma. Cancer Res 2010;70: 7640-7651

53. Guo Z, Zhang L, Wu Z, Chen Y, Wang F, Chen G. In vivo direct reprogramming of reactive glial cells into functional neurons after brain injury and in an Alzheimer's disease model. Cell Stem Cell 2014;14:188-202

54. Jayawardena TM, Egemnazarov B, Finch EA, Zhang L, Payne JA, Pandya K, Zhang Z, Rosenberg P, Mirotsou M, Dzau VJ. MicroRNA-mediated in vitro and in vivo direct reprogramming of cardiac fibroblasts to cardiomyocytes. Circ Res 2012;110:1465-1473

55. Song G, Pacher M, Balakrishnan A, Yuan Q, Tsay HC, Yang D, Reetz J, Brandes S, Dai Z, Pützer BM, Araúzo-Bravo MJ, Steinemann D, Luedde T, Schwabe RF, Manns MP, Schöler HR, Schambach A, Cantz T, Ott M, Sharma AD. Direct reprogramming of hepatic myofibroblasts into hepatocytes in vivo attenuates liver fibrosis. Cell Stem Cell 2016;18:797-808

56. Bankaitis ED, Ha A, Kuo CJ, Magness ST. Reserve stem cells in intestinal homeostasis and injury. Gastroenterology 2018;155:1348-1361 